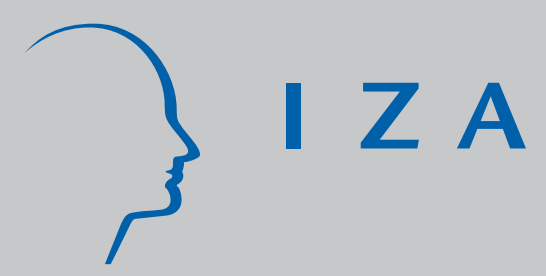

IZA DP No. 532

From Unemployment Benefits to Unemployment Accounts

J. Michael Orszag

Dennis Snower

J uly 2002 


\title{
From Unemployment Benefits to Unemployment Accounts
}

\author{
J. Michael Orszag \\ Watson Wyatt and IZA Bonn \\ Dennis Snower \\ Birkbeck College, University of London, \\ CEPR and IZA Bonn
}
Discussion Paper No. 532
July 2002

\author{
IZA \\ P.O. Box 7240 \\ D-53072 Bonn \\ Germany \\ Tel.: +49-228-3894-0 \\ Fax: +49-228-3894-210 \\ Email: iza@iza.org
}

This Discussion Paper is issued within the framework of IZA's research area Welfare State and Labor Market. Any opinions expressed here are those of the author(s) and not those of the institute. Research disseminated by IZA may include views on policy, but the institute itself takes no institutional policy positions.

The Institute for the Study of Labor (IZA) in Bonn is a local and virtual international research center and a place of communication between science, politics and business. IZA is an independent, nonprofit limited liability company (Gesellschaft mit beschränkter Haftung) supported by the Deutsche Post AG. The center is associated with the University of Bonn and offers a stimulating research environment through its research networks, research support, and visitors and doctoral programs. IZA engages in (i) original and internationally competitive research in all fields of labor economics, (ii) development of policy concepts, and (iii) dissemination of research results and concepts to the interested public. The current research program deals with (1) mobility and flexibility of labor, (2) internationalization of labor markets, (3) the welfare state and labor markets, (4) labor markets in transition countries, (5) the future of labor, (6) evaluation of labor market policies and projects and (7) general labor economics.

IZA Discussion Papers often represent preliminary work and are circulated to encourage discussion. Citation of such a paper should account for its provisional character. A revised version may be available on the IZA website (www.iza.org) or directly from the author. 
IZA Discussion Paper No. 532

July 2002

\begin{abstract}

\section{From Unemployment Benefits to Unemployment Accounts}

We explore the implications of replacing current unemployment benefit (UB) systems by unemployment accounts (UA). Under the UA system, employed people would be required to make ongoing contributions to their unemployment accounts, and the balances in these accounts would then be available to them during periods of unemployment. The government would be able to undertake balanced-budget redistributions among the UAs, taxing the contributions of the rich and subsidizing those of the poor. When people retire, they could use their remaining UA balances to top up their pensions. Under the unemployment benefit system, people are in effect rewarded for being unemployed (through the unemployment benefits) and penalized for being employed (through the taxes that finance the unemployment benefits). The UA system alleviates these externality problems. For when an unemployed person makes withdrawals from his UA, he is thereby diminishing the amount of funds that are available to him later on.
\end{abstract}

JEL Classification: J23, J32, J38, J64, J65, J68

Keywords: unemployment benefits, unemployment accounts, redistribution, employment, unemployment, pensions

Dennis Snower

Department of Economics

Birkbeck College

University of London

7 Gresse Street

London W1P 1PA

Tel.: +44 (207) 6316408

Email: dsnower@economics.bbk.ac.uk 


\section{INTRODUCTION}

This paper explores the implications of a far-reaching proposal for the reform of labor market policy: to replace current unemployment benefit (UB) systems by unemployment accounts (UA). Under the UA system, employed people would be required to make ongoing contributions to their unemployment accounts, and the balances in these accounts would then be available to them during periods of unemployment. The government would be able to undertake balanced-budget redistributions among the UAs, taxing the contributions of the rich and subsidizing those of the poor.

The mechanics of the UA system may be summarized as follows. Each employed person would make a fixed mandatory minimum contribution to his or her UA each month. Voluntary contributions above the mandatory minimum levels would be permitted as well. Upon becoming unemployed, an individual would be entitled to withdraw a fixed maximum amount per month from his or her UA. Smaller withdrawals would also be permitted.

When a person's UA balance falls to zero, he or she would become entitled to unemployment assistance, on the same financial terms as under the current unemployment benefit systems. In addition, the government could subsidize the contributions of people with low incomes. The unemployment assistance and contribution subsidies would be financed through taxes on the contributions of the other UA holders. When people retire, they could use their remaining UA balances to top up their pensions.

The UA system could be run on a pay-as-you-go (PAYG) or fully funded basis. ${ }^{1}$ If the UA system were fully funded, then the contribution rates could be set in an actuarially fair manner so that, for all the UAs of a

\footnotetext{
${ }^{1}$ This aspect is potentially important, for a standard criticism of personalized accounts in other areas of the welfare state (such as pensions, health care, or education) is that they are
} 
particular age cohort in the economy, the discounted value of aggregate minimum benefits is equal to the discounted value of aggregate contributions. ${ }^{2}$ If the UA system were run on a PAYG basis, such crosssubsidization of accounts would also extend across generations. In particular, a part of the UA balances of young people would finance the withdrawals of older people.

Since the UA system is compatible with both the PAYG and fully funded schemes, the transition from the former to the latter can proceed at whatever pace political and demographic conditions dictate. The closer the system is to being fully funded, the more discretion people could be given in determining who is to manage their UAs, the government or private ancestor financial institutions. The investment activity of the latter institutions would have to be regulated in order to minimize the risk of bankruptcy and provide adequate insurance.

The case for switching from unemployment benefits to UAs is straightforward. Under the unemployment benefit system, people are in effect rewarded for being unemployed (through the unemployment benefits) and penalized for being employed (through the taxes that finance the unemployment benefits). The UB system thereby creates an externality, since the unemployed impose costs on the employed. The unemployed, responding only to their private costs and benefits, do not take the full social costs of their unemployment into account when seeking jobs. In this way, the unemployment benefit system depresses job search and thereby stimulates unemployment. Furthermore, the employed do not receive full compensation for the social benefits from their employment and thus, if the relevant substitution effect dominates the income effect, they will work less hard than they otherwise would have. Thereby, the unemployment benefit system may depress productivity and thereby reduce employment. 
The UA system alleviates these externality problems. For when an unemployed person makes withdrawals from his UA, he is thereby diminishing the amount of funds that are available to him later on. Thus, in comparison with the UB system, the unemployed with UAs internalize more of the social costs of their unemployment and thus have greater incentives to search for jobs. When an employed person makes contributions to his UA, he is thereby increasing the account balance that he can draw on in the future. Thus employed people internalize more the benefit from their UA contributions than from the taxes they pay to finance unemployment benefits, and consequently, the UA system may give them more of an incentive to be productive than the unemployment benefit system.

Naturally, the degree to which the UA system mitigates the above externality problem depends on the government's redistributive goals. The more income the government redistributes from rich to poor, the greater the associated externality problem. Nevertheless, for any given amount of redistribution, the improved incentives under the UA system are likely to lead to higher employment, lower unemployment, and higher productivity than under the corresponding UB system.

This paper provides an analytical framework for exploring the implications of the switch from unemployment benefit to unemployment accounts. Section 2 presents a basic model of employment and unemployment under the two systems. Section 3 examines the government budget constraint ensuring that both systems are self-financing. Section 4 investigates microfoundations of the hiring and firing rates under the two systems and, on this basis, Section 5 presents a specific analytical example of how the two systems compare. Section 6 concludes.

\footnotetext{
${ }^{2}$ This method could ensure that generational accounts are in balance. But since some of the UA balances of high-income individuals would be used to subsidize the contributions of lowincome individuals, the contribution rates would not be actuarially fair for each individual.
} 


\section{THE MODEL}

Workers in our model live for two periods. In the first period of working life the worker is "young"; in the second period he is "old." The worker's possible labor market states are illustrated in Figure (1).

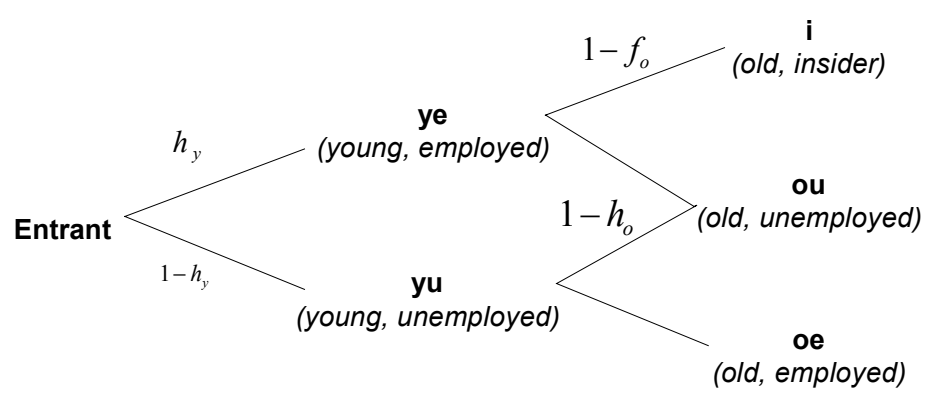

\section{Figure 1: Structure of the Model}

Upon entering the workforce, a each young worker faces a predetermined probability $h_{y}$ of becoming employed and a probability $1-h_{y}$ of remaining unemployed. Let and be the discounted lifetime utilities of a young employed worker be $V(y, e)$ and of a young unemployed worker be $V(y, u)$. Then the discounted lifetime utility of an entrant to the workforce is:

$$
V(y)=h_{y} V(y, e)+\left(1-h_{y}\right) V(y, u)
$$

A young, employed worker $(y, e)$ faces a probability $f_{o}$ of being fired at the beginning of the second period, in which case he turns into an old, unemployed $(o, u)$ worker . With probability $1-f_{o}$ the young, employed worker is retained in the second period, in which case he turns into an "insider" (i).

Finally, a young, unemployed worker $(y, u)$ faces a probability $h_{o}$ of being hired at the beginning of the second period, whereupon he becomes an "old entrant" $(o, e)$. With probability $1-h_{o}$ the young, unemployed worker does not find a job in the second period, 
so that he becomes an old unemployed worker .

For simplicity, we assume that entrants to the workforce devote all their time to job search, and thus the hiring rate for entrants $\left(h_{y}\right)$ may be taken as an exogenously given constant. Furthermore, we assume that the leisure of old workers is fixed. (Regardless of how much leisure they choose, they are assumed to maintain their current employment state and retire in the following period. Thus their leisure decision is not of interest with regard to the incentives generated by UB versus UA systems.) Thus, in the context of this model, the search and work incentives generated by UB and UA systems can be assessed simply by examining the leisure decisions of young workers.

Young unemployed workers divide their time between leisure and job search; young employed workers divide their time between leisure and work. The hiring rates in our model depend on job search intensity (i.e., the length of time unemployed workers spend searching), and the firing rates depend on productivity (i.e., the length of time spent working). Workers make their search-leisure and work-leisure choices so as to maximize their discounted lifetime utilities, taking into account the effects of these choices on the hiring and firing rates. ${ }^{3}$

The hiring rate $h_{o}\left(l_{y u}\right)$ for young unemployed workers depends inversely on their leisure $\left(l_{y u}\right)$; for the more leisure they choose, the less time they spend on job search and thus the fewer jobs they are likely to find. The firing rate for young employed workers $f_{o}\left(l_{y e}\right)$ depends inversely on their leisure $\left(l_{y e}\right)$; workers who shirk when young are more likely to be fired by the firm and are also less likely to be productive when old because of "learning by doing." Microfoundations of the hiring and firing rates are developed in Section 4.

\footnotetext{
3 The model is a simple two-period variant of the labor market model developed by Phelps (1994, ch. 15). Our innovations include the incorporation of job search and the analysis of unemployment accounts in this setting.
} 


\subsection{The Unemployment Benefit System}

Under an unemployment benefit system, let each unemployed worker receive an exogenously given real unemployment benefit $b$. Furthermore, let unemployment benefits be financed through a payroll tax, where $\tau$ is the payroll tax rate. Capital markets are incomplete so that young workers are unable to borrow against their future incomes.

The young unemployed worker receives the unemployment benefit $b$ in the first period, and the corresponding utility is $u\left(b, l_{y u}\right)$, where $l_{y u}$ is the worker's leisure. In the second period, with probability $h_{o}\left(l_{y u}\right)$, he gains the utility $V^{b}(o, e)$ of an old entrant, and with probability $1-h_{o}\left(l_{y u}\right)$ he gains the utility $V^{b}(o, u)$ of an old, unemployed worker. Since the leisure of the old workers is fixed, $V^{b}(o, e)$ and $V^{b}(o, u)$ are constants. (The superscript " $b$ " stands for the unemployment "benefit" system.)

Thus, the decision problem of the young unemployed worker may be represented as finding the level of leisure $l_{y u}$ that maximizes the following discounted utility:

$$
V^{b}(y, u)=\max _{l_{y u}} \dot{e}_{e} u\left(b, l_{y u}\right)+b\left(h_{o}\left(l_{y u}\right) V^{b}(o, e)+\left(1-h_{o}\left(l_{y u}\right)\right) V^{b}(o, u)\right) \text { 产 }
$$

where $b$ is the time discount factor. The first-order condition for this decision problem is:

$$
u_{l_{y u}}=-b h_{o}^{\prime}\left(l_{y u}\right)\left\{V^{b}(o, e)-V^{b}(o, u)\right\}
$$

In other words, the marginal utility of leisure must be set equal to the discounted marginal hiring propensity $\left(b h_{o}^{\prime}\left(l_{y u}\right)\right)$ times the reward for finding a job $\left(V^{b}(o, e)-V^{b}(o, u)\right)$. Since there is diminishing marginal utility of leisure, the optimal level of leisure depends inversely on the reward for finding a job.

Along similar lines, the young employed worker receives the wage $w(1-t)$ in the first period; in the second period, with probability $f_{o}\left(l_{y e}\right)$, 
he gains the utility $V^{b}(o, u)$ of an old, unemployed worker, and with probability $1-f_{o}\left(l_{y e}\right)$, he gains the utility $V^{b}(o, e)$ of an old, employed worker. (As above, the utilities $V^{b}(o, u)$ and $V^{b}(o, e)$ are constants, since the leisure of the old workers is fixed.)

Thus the young employed worker's decision problem is to find the level of leisure that maximizes the following discounted utility:

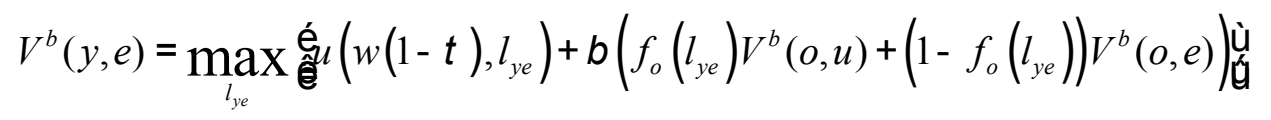

The first-order condition for this problem is:

$$
u_{l_{y e}}=b f_{o}^{\prime}\left(l_{y e}\right)\left\{V^{b}(o, e)-V^{b}(o, u)\right\}
$$

Here, the marginal utility of leisure must be set equal to the discounted marginal firing propensity $\left(b f_{o}^{\prime}\left(l_{y e}\right)\right)$ times the penalty for job loss $\left(V^{b}(o, e)-V^{b}(o, u)\right)$. Once again, diminishing marginal utility of leisure implies that the optimal level of leisure depends inversely on the penalty for job loss. ${ }^{4}$

\subsection{The UA System.}

Now consider the workers' choices under the UA system. For comparability, we assume that the interpersonal redistributions among the accounts are such that the unemployed always receive an amount at least as large as the unemployment benefit $b$. Specifically, if a young worker is unemployed, he receives $b$, and gains utility $u\left(b, l_{y u}\right)$. Since he is unemployed, he is unable to accumulate positive UA balances in the second period. With probability $h_{o}$, he finds a job in the second period and gains utility $V^{a}(o, e, 0)$, where the superscript "a" stands for "accounts, "o,e" stands for an "old entrant" worker, and " 0 " stands for the level of that worker's account balances. With probability $1-h_{o}$, he finds no job in the second period and

\footnotetext{
${ }^{4}$ This is true if leisure and consumption are complements. Otherwise, consumption and leisure must not be strong enough substitutes for the decrease in period one consumption
} 
gains utility $V^{a}(o, u, 0)$, where " $o, u$ " stands for "old unemployed". As above, $V^{a}(o, e, 0)$ and $V^{a}(o, u, 0)$ are constants. Thus the young unemployed worker's decision problem is to maximize

$$
\left.V^{a}(y, u)=\max _{l_{y u}} \hat{e ̂ ́}_{\hat{e}}\left(b, l_{y u}\right)+b\left(h_{o}\left(l_{y u}\right) V^{a}(o, e, 0)+\left(1-h_{o}\left(l_{y u}\right)\right) V^{a}(o, u, 0)\right)\right)_{\hat{\theta}}^{u ̀}
$$

The first-order condition is

$$
u_{l_{y u}}=-b h_{o}^{\prime}\left(l_{y u}\right)\left\{V^{a}(o, e, 0)-V^{a}(o, u, 0)\right\}
$$

If a young worker is employed, she receives the wage $w$. Denote her optimal level of consumption in period 1 by $c^{*}$. Then the contribution to her $\mathrm{UA}$ is $\left(w-c^{*}\right)$. Let $r$ be the interest rate and $k$ be the rate at which her contribution is taxed (both exogenously given to the worker). Then her account balance in the following period will be $A=\left(w-c^{*}\right)(1+r)(1-k)$. Thus the young employed worker's decision problem is to maximize

$$
\left.V^{a}(y, e)=\max _{l_{y e}} \mathrm{e}_{i} u\left(w(1-t), l_{y e}\right)+b\left(f_{o}\left(l_{y e}\right) V^{a}(o, u, A)+\left(1-f_{o}\left(l_{y e}\right)\right) V^{a}(o, e, A)\right)\right)_{\hat{G}}^{\grave{a}}(2.8)
$$

and the corresponding first-order condition is

$$
u_{l_{y e}}=b f_{o}^{\prime}\left(l_{y e}\right)\left\{V^{a}(o, e, A)-V^{a}(o, u, A)\right\}
$$

Define the replacement ratio as $v=(b / w)$ and the contribution rate under the UA system as $k=\left(w-c^{*}\right) / w$. In order for the young employed worker's UA contribution to be sufficiently high to yield at least as much as the unemployment benefit, should he become unemployed when old, we require that $A=\left(w-c^{*}\right)(1+r)(1-k)>b$, which implies that :

$$
k^{3} \frac{n}{(1+r)(1-k)}
$$

In what follows, we presuppose that this condition holds. In addition, the tax rate must be set so that total tax receipts are sufficient to fund payments of to each unemployed person with insufficient account balances, i.e. to each young and old unemployed person. This government budget constraint is examined in Section 3. 


\subsection{A Preliminary Comparison of the Two Systems.}

It is important to observe that the first-order conditions for utility maximization under the UB and UA systems are virtually identical. In both cases, job search and work effort depend crucially on the difference between the value of being employed and that from being unemployed. This difference, however, varies across the two systems and on this account the work and search incentives generated by the two systems differ as well.

Table (1) compares the two systems by describing period-2 consumption as a function of the worker's labor market history.

\begin{tabular}{|l|l|l|}
\hline & Unemployment Benefit System \\
\hline & Employed & Unemployed \\
\hline Period 1 Employed & $w(1-t)$ & $b$ \\
\hline Period 1 Unemployed & $w(1-t)$ & $b$ \\
\hline & Account System & Unemployed \\
\hline & Employed & $\left(w-c^{*}\right)(1+r)(1-k)$ \\
\hline Period 1 Employed & $w+\left(w-c^{*}\right)(1+r)(1-k)$ & $b$ \\
\hline Period 1 Unemployed & $w$ & \\
\hline
\end{tabular}

Table 1: Period 2 Consumption as a Function of Period 1 and Period 2 States

To make the comparison transparent, suppose that all workers receive the same, exogenously given wage. Under the UB system, workers receive $w(1-t)$ when employed, and $b$ when unemployed; thus they stand to lose $\mathrm{L}=w(1-t)-b$ from being unemployed.

Under the UA system, by contrast, the incentives are quite different. Consider old workers who were previously employed. If continue to be employed, they receive $w+k w(1-k)(1+r)$; and if they become unemployed, they receive $k w(1-k)(1+r)$. The difference is $w$, which is larger than the 
corresponding difference $\mathrm{L}=w(1-t)-b$ under the UB system. ${ }^{5}$ As for old workers who were previously unemployed, they receive $w$ when gaining employment and $b$ when remaining jobless. The resulting difference, $w$ - $b$, is also larger than .

In short, under the UA system, workers stand to lose more from being unemployed than under the UB system, since they internalize more of the costs of their unemployment than under the unemployment benefit system. In the first-order conditions (2.3), (2.5), (2.7),(2.9), we have seen that the workers' leisure decisions depend positively on the penalty for job loss. Consequently, the unemployed have the incentive to search harder for jobs (take less leisure while unemployed) and the employed are induced to work harder (take less leisure while employed) under the UA system.

As result, it is straightforward to see that unemployment will be lower under the UA system. Specifically, normalizing the size of each age cohort to 1, the aggregate unemployment level is:

$$
U_{o}=h_{y} f_{o}\left(l_{y e}\right)+\left(1-h_{y}\right)\left(1-h_{o}\left(l_{y u}\right)\right)
$$

Since $l_{y e}$ and $l_{y u}$ are both lower under the UA system than under the unemployment benefit system, the firing rate $f_{o}$ will be lower and the hiring rate $h_{o}$ will be higher under the former system. Thus the UA system generates less unemployment.

\section{The Government Budget Constraint}

The government budget constraint under the UB system specifies that the discounted expected present value of unemployment benefits must be equal to the discounted expected present value of the taxes that finance those benefits:

\footnotetext{
${ }^{5}$ The same result holds in utility terms for any concave utility function :$$
g(w+k w(1-\kappa)(1+r))-g(k w(1-\kappa)(1+r))>g(w(1-\tau))-g(b)
$$$$
\text { We note that by concavity, }
$$$$
g(w+k w(1-\kappa)(1+r))>g(w)+g(k w(1-\kappa)(1+r)),
$$ 


$$
b\left(\left(1-h_{y}\right)+\beta U_{o}\right)=w \tau\left(h_{y}+\beta\left(1-U_{o}\right)\right)
$$

with second period unemployment $U_{o}$ determined by Eq. (2.11).

Thus the payroll tax rate under the UB system is:

$$
\tau=\frac{b}{w} \frac{\left(1-h_{y}\right)+\beta U_{o}}{h_{y}+\beta\left(1-U_{o}\right)}
$$

By Eq. (2.13), the payroll tax level is increasing in both the leisure of the employed and unemployed.

Under the UA system, by contrast, only those who are unemployed in both periods receive unemployment benefits. The unemployment benefits in both periods are funded out of taxes on the contributions of the young employed. The expenditure on those unemployed in period 1 is $b\left(1-h_{y}\right)$ and that on the period 2 unemployed is $b\left(1-h_{y}\right)\left(1-h_{o}\left(l_{y u}\right)\right) /(1+r)$, and the amount of revenue is $\kappa k w h_{y}$. Hence the tax rate on the UA contributions is

$$
\kappa=\left[\frac{\left(1-h_{o}\left(l_{y u}\right)\right)}{(1+r)}+1\right] \frac{1-h_{y}}{h_{y} k} v
$$

Suppose that the goal of the system is only to replicate the existing replacement ratio $v$ so that $k=\frac{v}{(1+r)(1-\kappa)}$ then the level of necessary to sustain the system is relatively low. For example suppose that $h_{y}=0.90$ and that $h_{o}\left(l_{y u}\right)=0.90$ and $f_{o}\left(l_{y e}\right)=0.10$, then unemployment in the first period is $10 \%$ and of these people $90 \%$ find jobs so that only $1 \%$ need benefits in the second period. If the discount rate is $10 \%$, the amount of benefits that need to be funded in period 2 units:

$$
0.10(1.10)+0.01=0.12 b
$$

The $90 \%$ of people who are employed in period 1 and contributing to the system with an aim of replicating unemployment benefits if unemployed pay a contribution need to pay for this, meaning that the tax rate on contributions is about $11.76 \%$.

so that $g(w+k w(1-\kappa)(1+r)) \geq g(w)>g(w(1-\tau))-g(b)$. 


\section{Microfoundations of Hire and Fire Rates}

We have assumed that the only way workers perceive they can influence hire and fire is through the choice of leisure. In this section, we provide some microfoundations for such hire and fire rates. There are a variety of models which can produce the same outcomes; here, we only illustrate the simplest possible model.

There are a large number $\mathrm{M}$ of firms, each of which has workers and maximizes its two period profits :

$$
F(L, 1)=\left[\Gamma\left(0, l_{y e}\right)-w_{y}-d f_{o}\right] L-\varpi \omega N \frac{U_{y}}{M}+\beta \pi_{2}
$$

with:

$$
\pi_{2}=\left(\Gamma\left(\psi, l_{y e}\right)-w_{i}\right)\left(1-f_{o}\right) L+\left(\Gamma\left(0, l_{y e}\right)-w_{o}\right) \omega N \frac{U_{y}}{M}
$$

Here, $\beta$ is the discount rate, $\psi$ captures learning by doing in production, $\Gamma$ is productivity which depends on experience and effort, $w_{y}$ is the wage in period $1, w_{o}$ is the wage of those unemployed in period 1 who become employed in period 2, $w_{i}$ is the "insider" wage in period 2 for those employed in period $1, d$ is the cost of firing a worker, $f_{o}$ is the firing rate, $\varpi$ is the cost of hiring a worker, $l_{o e}$ is the leisure of the old, $N$ is the number of interviews conducted with each of the period 1 $U_{y}$ unemployed workers and $\omega$ is the hiring rate at each interview.

Since the purpose of this section is to derive the microfoundations of hire and fire rates, we treat the wages $w_{i}, w_{o}$ and $w_{y}$ in the model as predetermined. We introduce these wages as separate parameters here because they separately influence the hire and fire decisions. The first order condition for hiring is that, if the firm is hiring, the shadow value of a worker exceeds the marginal hiring cost:

$$
\lambda=\beta\left(\Gamma\left(0, l_{o e}\right)-w_{o}\right)>\varpi
$$


When a worker comes for interviews at a firm, the firm's hiring decision is based on comparing the estimated shadow values $\lambda-\varepsilon$ (where $\varepsilon$ is a random variable) from hiring additional the employee with marginal training costs $\varpi$. At the interview time, the firm does not know how active the worker has been searching for a job so that its estimates of the shadow value are independent of the amount of search of the employee. The hire rate $\omega$ then is:

$$
\omega=H(\lambda-\varpi)
$$

where is the cumulative distribution function of $\varepsilon$.

Workers know the hire rate and have a time endowment of 1 when unemployed and obtaining an interview takes units of time. Workers who do one interview are hired with a probability $\omega$; if they are not hired (with probability $1-\omega$ ), they may proceed to a second interview and be hired with a probability $\omega$. The total probability of being hired is:

$$
h_{o}=\omega \sum_{j=0}^{N-1}(1-\omega)^{j}=1-(1-\omega)^{N}
$$

Given that the total endowment of leisure time is 1 , then $\mathrm{N}$ interviews take $c N$ units of time. Thus, leisure when unemployed is $1-c N$ so that $N=\frac{1-l_{y u}}{c}$. Hence:

$$
h_{o}\left(l_{y u}\right)=1-(1-\omega)^{\frac{1-l_{y u}}{c}}
$$

which is decreasing in the leisure when unemployed. A linear approximation to Eq. (3.6) is:

$$
h_{o}\left(l_{y u}\right)=1+\log (1-\omega) \frac{\left(l_{y u}-1\right)}{c}
$$

which can be rewritten as:

$$
h_{o}\left(l_{y u}\right)=\theta\left(1-a l_{y u}\right) .
$$

The hire rate function formulation implicitly assumes that workers 
take the wage as given. The first order condition of the profit maximization problem Eq. (3.1) for firing is that a worker will be fired if

$$
\beta\left(\Gamma\left(\psi, l_{y e}\right)-w_{i}\right)+d<0
$$

so that a worker is fired when his/her discounted future contribution to profits falls below minus marginal firing costs. Because the worker is working on projects which may take more than one period, his first period effort $l_{y e}$ will influence second period productivity. This effect is captured through the random parameter $\psi$ which measures learning by doing.

Since the learning by doing parameter is random, firing is stochastic and the probability of firing a worker is given by the probability that Eq. (27) is negative. To simplify analysis, we assume that $\Gamma\left(\psi, l_{y e}\right)$ is linear:

$$
\Gamma\left(\psi, l_{y e}\right)=\left(\varsigma-l_{y e}\right) \psi
$$

Hence, the probability of firing the worker is:

$$
f=G\left(\frac{\chi}{\varsigma-l_{y e}}\right)
$$

where $\mathrm{G}$ is the cumulative density function of $\psi$ and $\chi=\frac{\beta w-d}{\beta}$. Here, the fire rate is increasing in the level of leisure on the job $l_{y e}$ as well as increasing in the wage $w$. The cumulative density function can take a variety of forms but we can construct a first order approximation in terms of $l_{y e}$ about $l_{y e}=\bar{l}$ :

$$
f_{o}\left(l_{y e}\right)=\varphi+\phi l_{y e}
$$

Someone who exhibits full effort and does not shirk at all should not be fired which can be achieved by setting $\varphi=0$. Hence:

$$
f_{o}\left(l_{y e}\right)=\phi l_{y e}
$$

The parameter will depend on a number of other parameters including 
the wage. 6

\section{An Example}

In this section, we consider a simple example to illustrate the basic model described in Section 2. We consider the utility function:

$$
u(c, l)=\frac{\left(c^{\alpha} l^{1-\alpha}\right)^{\gamma}}{\gamma}
$$

In Sec. 4 above, we derived microfoundations for hiring and firing rates. This section suggests the choice of hire and fire rates of:

$$
\begin{gathered}
h_{o}\left(l_{y u}\right)=\theta\left(1-a l_{y u}\right) \\
f_{o}\left(l_{y e}\right)=\phi l_{y e}
\end{gathered}
$$

Again, as mentioned in Sec. 4, the parameters $\phi, \theta$ and $a$, which the worker treats as given, will typically be endogenous and depend on various aspects of the problem of profit maximization by the firm. We focus here only on the effects of funding on the consumer problem or alternatively assume that the firm treats the worker's supply of effort and leisure as given. Since $l_{o u}$ and $l_{o e}$ are treated as fixed in our model, we normalize their values to 1 .

\subsection{Unfunded Benefits}

When unemployed in the first period, the worker's problem is to solve:

$$
V^{b}(y, u)=\max _{l_{y u}}\left[\frac{\left(b^{\alpha} l_{y u}^{1-\alpha}\right)}{\gamma}+\frac{\beta}{\gamma}\left(h_{o}\left(l_{y u}\right)(w(1-\tau))^{\alpha \gamma}+\left(1-h_{o}\left(l_{y u}\right)\right) b^{\alpha \gamma}\right)\right]
$$

subject to:

\footnotetext{
${ }^{6}$ Another way of justifying this functional form for the firing function is in terms of a shirking model (c.f., (Phelps 1994), Ch. 15 for details).
} 


$$
\max \left[0, \frac{1}{a}\left(1-\frac{1}{\theta}\right)\right] \leq l_{y u} \leq \frac{1}{a}
$$

The interior solution for leisure when unemployed is:

$$
l_{y u}=\left[\frac{\beta a \theta}{(1-\alpha) \gamma}\left((w(1-\tau))^{\alpha \gamma}-b^{\alpha \gamma}\right)\right]^{\frac{1}{(1-\alpha) \gamma-1}} b^{-\frac{\alpha \gamma}{(1-\alpha) \gamma-1}}
$$

When employed in the first period, the worker's problem is to solve:

$$
V^{b}(y, e)=\max _{l_{y e}}\left[\frac{\left((w(1-\tau))^{\alpha} l_{y e}^{1-\alpha}\right)}{\gamma}+\frac{\beta}{\gamma}\left(\left(1-f_{o}\left(l_{y e}\right)\right)(w(1-\tau))^{\alpha \gamma}+f_{o}\left(l_{y e}\right) b^{\alpha \gamma}\right)\right]
$$

subject to:

$$
0 \leq l_{y e} \leq \frac{1}{\phi}
$$

which, assuming an interior solution, leads to an optimal choice of leisure of:

$$
l_{y u}=\left[\frac{\beta \phi}{(1-\alpha) \gamma}\left((w(1-\tau))^{\alpha \gamma}-b^{\alpha \gamma}\right)\right]^{\frac{1}{(1-\alpha) \gamma-1}}(w(1-\tau))^{-\frac{\alpha \gamma}{(1-\alpha) \gamma-1}}
$$

The unemployment rate in the second period is:

$$
U_{o}=\left(1-h_{y}\right) \theta+\phi l_{y e}+a \theta l_{y u}
$$

To determine the balanced budget payroll tax rate, we solve the equation:

$$
b\left(\left(1-h_{y}\right)+\beta U_{o}\right)=\tau w\left(h_{y}+\beta\left(1-U_{o}\right)\right)
$$

for $\tau$. Unfortunately, this equation cannot be solved analytically. However, it is simple to do so numerically.

As a simple example, we set $w=1.0, h_{y}=0.90, b=0.20, \phi=1.50$, $r=0.10, a=0.75, \theta=1.0, \alpha=0.75, \beta=\frac{1}{1+r}, \gamma=0.85$. In this case, the equilibrium payroll tax rate is $3.95 \%$ and the fire and hire rates are $25.3 \%$ and $91.4 \%$ respectively. The unemployment in period 2 is $23.7 \%$. In the next section, we will review how to do calculations for an account system. For these same parameter 
values, unemployment under a balanced account system in period 2 is or about half the level of the benefit system because of the effects on incentives.

\subsection{The Account System}

$$
V^{a}(y, u)=\max _{l_{l u}, c}\left[\frac{\left(b^{\alpha} l_{y u}^{1-\alpha}\right)}{\gamma}+\frac{\beta}{\gamma}\left(h_{o}\left(l_{y u}\right)(w)^{\alpha \gamma}+\left(1-h_{o}\left(l_{y u}\right)\right) b^{\alpha \gamma}\right)\right]
$$

subject to:

$$
\max \left[0, \frac{1}{a}\left(1-\frac{1}{\theta}\right)\right] \leq l_{y u} \leq \frac{1}{a}
$$

The interior solution for leisure when unemployed is:

$$
l_{y u}=\left[\frac{\beta a \theta}{(1-\alpha) \gamma}\left((w)^{\alpha \gamma}-b^{\alpha \gamma}\right)\right]^{\frac{1}{(1-\alpha) \gamma-1}} b^{-\frac{\alpha \gamma}{(1-\alpha) \gamma-1}}
$$

For the employed in period 1 , the problem is:

$V^{a}(y, e)=\max _{l_{y e}}\left[\frac{\left((c)^{\alpha} l_{y e}^{1-\alpha}\right)^{\gamma}}{\gamma}+\frac{\beta}{\gamma}\left(\left(1-f_{o}\left(l_{y e}\right)\right)(w+(w-c)(1+r)(1-k))^{\alpha \gamma}+f_{o}\left(l_{y e}\right)((w-c)(1+r)(1-k))^{\alpha \gamma}\right)\right]$

subject to:

$$
\begin{gathered}
0 \leq c \leq w-\frac{b}{(1+r)(1-k)} \\
0 \leq l_{y e} \leq \frac{1}{\phi}
\end{gathered}
$$

Fro any fixed level of $c$ 
$l_{y e}=\left[\frac{\beta \phi}{(1-\alpha) \gamma}\left((w+(w-c)(1+r)(1-k))^{\alpha \gamma}-((w-c)(1+r)(1-k))^{\alpha \gamma}\right)\right]^{\frac{1}{(1-\alpha) \gamma-1}} c^{\frac{-\alpha \gamma}{(1-\alpha) \gamma-1}}$

for an interior solution.

The balanced budget constraint is (c.f., Section 3):

$$
\kappa(w-c) h_{y}=b\left(\left(1-h_{y}\right)+\frac{\left(1-h_{y}\right)\left(1-\theta\left(1-a l_{y u}\right)\right)}{1+r}\right)
$$

The interpretation of Eq. (4.19) is that the tax on the contributions of employed in period 1 pays for the unemployed benefits of those who cannot afford to pay these benefits out of their accounts. In this simplified model, those without account assets are those who are un-employed in the first period and those who are unemployed in both the first and second periods.

As a simple example, we set $w=1.0, h_{y}=0.90, b=0.20, \phi=1.50, r=0.10$, $a=0.75, \phi=1, \alpha=0.75, \beta=\frac{1}{1+r}, \gamma=0.85$. In this case the equilibrium contribution rate is $7.72 \%$ and the fire and hire rates are 0.123 and 0.918 respectively. The unemployment in period 2 is $11.87 \%$ as opposed to $23.66 \%$ in the funded case. The maximum consumption ratio is $80.3 \%$ in period 1 as opposed to $96.05 \%$ in the benefit case; however, agents choose to consume only $40.2 \%$ of their wage. ${ }^{7}$

\subsection{Comparisons}

We have identified two principal channels whereby accounts reduce unemployment in the two period model:

- Increased effort when employed. Because costs are internalized there are larger penalties for job loss so that workers exhibit more effort.

- Increased search when unemployed. Internalization of costs leads workers to search more.

We now compare balanced budget behavior under the account and benefit systems. In Table (2) we report: unemployment under the benefit system in period $2\left(U_{0}^{u}\right)$ and the percentage change in unemployment from moving to a funded system with different

\footnotetext{
${ }^{7}$ The intuition for this is that consumption and leisure are complements and agents will have higher leisure in the second period.
} 
values of the replacement ratio $v=\frac{b}{w}$, firm monitoring/fire rate $\phi$, search cost parameter $a$ and hiring propensity $\theta$. We fix $h_{y}=0.90, w=1, r=0.10, \gamma=0.85$. We find that the incentive effects of a funded system lead to significant employment reductions.

\begin{tabular}{|l|l|l|l|l|l|}
\hline$\frac{b}{w}$ & $\phi$ & $a$ & $\theta$ & $U_{0}^{u}$ & $\frac{\Delta U_{0}}{U_{0}^{u}}$ \\
\hline \hline 0.1 & 1.5 & 0.75 & 1.0 & 0.182115 & $-40.07 \%$ \\
\hline 0.2 & 1.5 & 0.75 & 1.0 & 0.236609 & $-49.84 \%$ \\
\hline 0.3 & 1.5 & 0.75 & 1.0 & 0.314233 & $-58.12 \%$ \\
\hline 0.2 & 2.0 & 0.75 & 1.0 & 0.219309 & $-56.54 \%$ \\
\hline 0.2 & 1.0 & 0.75 & 1.0 & 0.263485 & $-41.43 \%$ \\
\hline 0.2 & 0.5 & 0.75 & 1.0 & 0.317194 & $-36.92 \%$ \\
\hline 0.2 & 1.5 & 0.5 & 1.0 & 0.237618 & $-49.64 \%$ \\
\hline 0.2 & 1.5 & 0.2 & 1.0 & 0.240351 & $-49.10 \%$ \\
\hline 0.2 & 1.5 & 0.75 & 0.5 & 0.289315 & $-40.23 \%$ \\
\hline 0.2 & 1.5 & 0.75 & 0.25 & 0.317001 & $-36.47 \%$ \\
\hline
\end{tabular}

Table 2: Funded versus Unfunded Unemployment Benefits

These effects can also be seen in Fig. (2) for changes in the unemployment benefit replacement ratio. We note that the incentive effects of funding decrease the dependence of the unemployment rate on the replacement ratio as well as reducing overall unemployment. The intuition for this is that consumption and leisure are complements and agents will have higher leisure in the second period. In Fig. (3), we show the same effects for changes in the parameter $\phi$. In Fig. (4), we show the dependence of unemployment under the funded and benefit systems on $a$. Finally, in Fig. (5), we show the dependence of unemployment under the funded and benefit systems on $\theta$.

\section{Conclusions}

This paper analyzes the implications for unemployment of replacing the prevailing unemployment benefit systems with unemployment accounts (UAs). This shift involves replacing the current system of payroll taxes and unemployment benefits with a system of mandatory contributions and 
withdrawal rules. Under our proposal, the government will use a balanced budget redistribution mechanism to provide benefits to those who cannot afford to pay out of their UAs.

Unemployment in our model is equilibrium unemployment in the sense of Phelps (1994) and Lindbeck and Snower (1988) in that there are explicit hire and fire costs; while workers choose leisure, their choice of leisure influences their transition probabilities between states rather than the level of hours worked. Workers who cannot afford to pay for unemployment benefits out of their accounts receive unemployment benefits which are funded by contributory taxes on those who contribute to accounts.

Our model shows that unemployment accounts lead to significant decreases in unemployment because the account system leads to substantial increases in the penalties for losing or not finding a job. These stronger penalties lead workers to search and work harder; because hire rates rise and fire rates fall, balanced budget unemployment is lower in the account system relative to the current system of unemployment benefits.

\section{References}

Lindbeck, Assar, and Dennis J. Snower (1988), The Insider-Outsider Theory of Employment and Unemployment, Cambridge, Mass: MIT Press.

Phelps, Edmund S. (1994), Structural Slumps, Cambridge, Mass: Harvard University Press. 


\section{IZA Discussion Papers}

No. Author(s)

515

J. Hurley

R. Vaithianathan

T. F. Crossley

D. Cobb-Clark

$516 \quad$ H. Bonin

517

518 P. Carneiro

J. J. Heckman

519

520

521
R. Fahr

S. $-\AA$ Å. Dahl

$\varnothing$. A. Nilsen

K. Vaage

J. Falkinger
V. Grossmann
J. J. Dolado
F. Felgueroso
J. F. Jimeno
J. J. Heckman
C. Heinrich
J. Smith
E. Leuven
H. Oosterbeek

J. C. van Ours

\section{P. Manzini}

M. Mariotti

J. M. Orszag

D. Snower

M. Karanassou

D. Snower

M. Karanassou

H. Sala

D. Snower
J. M. Orszag

D. Snower
Title

Area

Date

Parallel Private Health Insurance in Australia:

3

06/02

A Cautionary Tale and Lessons for Canada

Eine fiskalische Gesamtbilanz der Zuwanderung

7 nach Deutschland

Child Care Subsidies, Wages, and Employment 3

of Single Mothers

The Evidence on Credit Constraints in

5

06/02

Post-Secondary Schooling

Labor Mobility of Immigrants: Training,

Experience, Language and Opportunities

Unobserved Bilateral Search on the Labor

Market: A Theory-Based Correction for a

Common Flaw in Empirical Matching Studies

Employment Status, Endogenous Regional

Mobility, and Spatial Dependencies in Labor

Markets

Gender Differences in Early Retirement

Behaviour

Workplaces in the Primary Economy and Wage 3

Pressure in the Secondary Labor Market

Recent Trends in Occupational Segregation by

2

Gender: A Look Across the Atlantic

The Performance of Performance Standards

6

07/02

A New Approach to Estimate the Wage Returns to Work-Related Training

$07 / 02$

The Locking-in Effect of Subsidized Jobs

4

07/02

Arbitration and Mediation: An Economic

3

07/02

Perspective

Incapacity Benefits and Employment Policy

07/02

Unemployment Invariance

07/02

Unemployment in the European Union: A

Dynamic Reappraisal

07/02

An updated list of IZA Discussion Papers is available on the center's homepage www.iza.org.

From Unemployment Benefits to Unemployment 3 Accounts 